\title{
Da violência contra a Bíblia: a tradução de Sl 53,6
}

\author{
From violence against the Bible: \\ the translation of $\mathrm{Sl} 53,6$
}

Osvaldo Luiz Ribeiro ${ }^{1}$

\begin{abstract}
Resumo: O artigo relaciona o conceito de violência ao de tradução irregular da Bíblia Hebraica. Nesse sentido, traduções ideologicamente comprometidas, com implicações inclusive gramaticais, são tratadas como casos de violência contra a Bíblia. Para a demonstração, analisam-se traduções de Sl 53,6 em versões nacionais, comparando -as diretamente com o tex to hebraico e tradução do pesquisador. Conclui-se que o que pode ser interpretado como dificuldades na compreensão do tex to resultam na desconsiederação dos termos constantes no texto em tradução. O resultado é uma tradução que, na prática, impede que o leitor das ve rsões possa, por ele mesmo, compreender o que o tex to hebraico supostamente traduzido pretendia dizer.
\end{abstract}

Palav ras-chave: tradução; $\mathrm{Sl}$ 53,6; exegese.

Abstract: The article relates the concept of violence to the concept of irregular translation of the Hebrew Bible. In this sense, ideologically committed translations, with even grammatical implications, are treated as cases of violence against the Bible. For the demonstration, translations of Ps 53,6 in national versions are analyzed, comparing them directly with the Hebrew text and the translation of the researcher. We conclude that what can be interpreted as difficulties in understanding the text results in the disregard of the terms in the text in translation. The result is a translation which, in practice, prevents the reader of the versions from being able to understand for himself what the Hebrew text supposedly translated meant. Keywords: translation; Ps 53:6; exegesis

Artigo recebido em: 06 fev. 2018 Aprovado em: 03 ago. 2018

${ }_{1}^{1}$ Pós-doutor em Ciências da Religião (UFJF), doutor em Teologia (PUCRio). Professor da Faculdade Unida de Vitória. 


\section{Introdução}

Sl 53 é um salmo fascinante. Quem o compôs é mestre poeta, artífice escritor, mágico retórico, e, não bastasse isso, um analista político-social invejável. Tenho dificuldades em aceitar que o Sl 53 seja a versão "secundária" do Sl $14^{2}$. Tratase do mesmo salmo, obviamente, mas quero crer que o Sl 53 seja o original. Ao menos uma regra da hermenêutica de textos antigos autoriza a declaração: textos "mais difíceis" são, em tese, mais antigos do que suas versões "mais fáceis" de ler e entender ${ }^{3}$. Nesse caso, o v. 64 é quase que completamente diferente nos dois salmos, o que resulta necessário concluir que o problema da composição original fora justamente esse verso. Pois bem, Sl 53,6 não é de difícil tradução, mas, ao mesmo tempo, não é de fácil interpretação. Já quanto à seção correspondente do Sl 14, nesse caso, Sl 14,5-6, nem a tradução

2 Refiro-me à opinião de Alonso-Schökel e Carniti, que consideram o Sl 53 secundário em relação ao $\mathrm{Sl}$ 14, e ainda o dão por estado de conservação pior do que o 14 (ALONSO-SCHÖKEL, L. e CARNITI, C. Salmos I. Salmos 1-72. São Paulo: Paulus, 1996, p. 249-261 e 717-718). Essa é igualmente a posição de Kraus (KRAUS, H. Los Salmos. Volumen I. Salmos 1-59. Salamanca: Sígueme, 2009, p. 337-348) e de Weiser (WEISER, A. Os Salmos. São Paulo: Paulus, 1994, p. 115-117). Alonso-Schökel ainda reservam algumas páginas para o comentário em separado do $\mathrm{Sl} 53$, mas Kraus e Weiser parecem tão seguros da condição secundária, logo, "inferior", do $\mathrm{Sl} 53$, que não apresentam comentários à parte, fazendo-o apenas para o $\mathrm{Sl}$ 14. A despeito da autoridade dos autores citados, insista-se na regra hermenêutica.

3 Note-se que, considerando o $\mathrm{Sl} 53$ uma segunda transmissão, com variantes, do $\mathrm{Sl}$ 14, o próprio Kraus acrescenta que "a forma do texto no $\mathrm{Sl}$ 53 (especialmente em 53,6) é mais complicada e menos transparente que no Sl 14" (KRAUS, 2008, p. 341). Quanto à regra mencionada, trata-se do princípio lectio difficilior potior, segundo o qual, se há duas versões de um mesmo texto, e uma delas impõe ao leitor uma leitura "mais difícil", prov avelmente esta é a versão original, e a de leitura "mais fácil", a variante (TREBOLLE BARRERA, J. A Bíblia judaica e a Bíblia cristã. 2 ed. Petrópolis: Vozes, 1999, p. 452). Tanto Kraus quanto Alo nso-Schökel e Carniti não aplicaram a regra ao caso.

4 No hebraico; nas versões evangélicas, o v. 5. Além disso, ao v. 6 do Sl 53, correspondem os v. 5-6 do Sl 14. Kraus deposita justamente nesse verso a razão de sua impressão quanto à má preservação do Sl 53 (cf. KRAUS, 2008, p. 341). A despeito da autoridade do autor, não há razão objetiva para se considerar assim. 
nem a interpretação são particularmente difíceis, tendo sido substancialmente descaracterizado o conteúdo político do verso (original) do Sl 535. Nesse caso, nos termos da regra citada, é mais adequado considerar que o Sl 53 seja o original e, por conta de problemas que se evidenciam particularmente no v. 6, talvez justamente problemas políticos, uma versão "corrigida" tenha sido elaborada, eventualmente para substituir a anterior, resultando, contudo, que, no fim das contas, as duas versões ${ }^{6}$ tenham sobrevivido ao tempo e tenham findado compondo o mesmo conjunto de textos sagrados.

A despeito de não se acatar a tese de Kraus quanto à má preservação do $\mathrm{Sl} 53,6$, aqui se assume que o v. 6 é o centro nevrálgico do $\mathrm{Sl}$ 53. Também se deve registrar que, a despeito da relativamente pouca dificuldade de tradução que oferece, nas versões analisadas há problemas relativamente sérios de tradução de Sl 53,6. Será necessário analisar o verso inteiro, identificar os problemas pontuais de tradução e, assim, evidenciar onde incide o problema hermenêutico em questão.

\section{Aproximação inicial ao Sl 53,6}

Não se fará uma exegese do Sl 53 aqui. Apenas Sl 53,6 será analisado, e, mesmo assim, com um objetivo específico: analisar o comportamento das versões brasileiras desse verso. Em termos procedimentais, a opção foi apresentar o texto hebraico, oferecer a tradução autoral da passagem e, ao fim, as traduções das versões, depois do que se poderão analisar as questões que envolvem a tradução do verso.

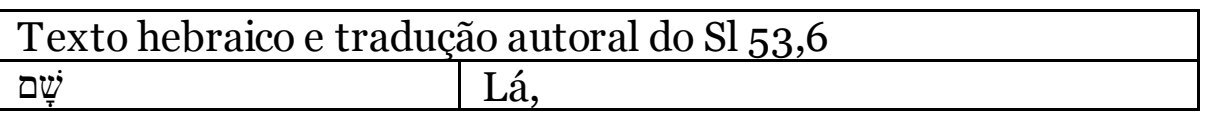

5 Cf. a nota h do Sl 53,6 na TEB: "diversamente do Sl 14,5-6, este verso se dirige a um representante da cidade” (BÍBLIA. Tradução ecumênica. 2 ed. São Paulo: Loyola).

6 Ainda que muito brevemente, Alonso-Schökel e Carniti ensaiam uma tentativa de explicação tanto do contexto específico do $\mathrm{Sl} 53$, quanto da preservação de duas variantes. A circunstanciação redacional do Sl $53 \mathrm{em}$ relação ao cerco de Jerusalém por Senaqueribe, cerca de 701 a.C., parecem adequadas (cf. ALONSO-SCHÖKEL e CARNITI, 1996, p. 718). 


\begin{tabular}{|c|c|}
\hline 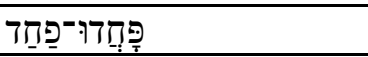 & aterrorizaram-se de terror, \\
\hline 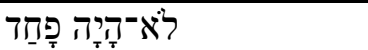 & sem que houvesse terror, \\
\hline 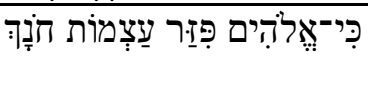 & $\begin{array}{l}\text { porque Deus espalhou os ossos do } \\
\text { que te sitiava. }\end{array}$ \\
\hline 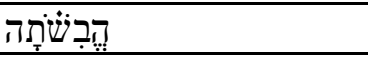 & Tu te envergonhaste, \\
\hline כִּי־אֶלדֶים מְאָסָם: & porque Deus os rejeitou. \\
\hline
\end{tabular}

Antes de perfilarmos as versões e compararmos o conjunto com o texto hebraico e a tradução autoral, é preciso considerar que o entendimento do texto é perfeitamente possível, sem o recurso a qualquer instância outra que não os procedimentos médios de leitura, que se podem dominar no Ensino Médio. Quando acima se disse tratar-se de uma tradução relativamente fácil, mas de uma interpretação um pouco mais sensível, quis-se fazer referência à estrutura sintática com que se constrói a oração. É preciso prestar alguma atenção mais dedicada ao fluxo narrativo, e acompanhar os saltos de referência que os termos sofrem. Poucas vezes Auerbach esteve tão certo quanto em relação a esse fragmento da literatura judaica antiga7. Todavia, o fato de, como considerou Auerbach, o estilo da narrativa concentrar-se no núcleo duro do enredo, o que exige do leitor "preencher" as lacunas do raciocínio narrativo, não deve se traduzir em decretação do estado de má preservação do Sl 53,6.

Sl 53,6 começa com uma cláusula adverbial: "lá” (שָָם). Isoladamente, não se poderia saber se se trata de uma cláusula de tempo ou lugar. Mas o texto dá indícios claros de que se trata, ao mesmo tempo, de ambos. O "lá" que abre a oração se refere ao cerco que a cidade sofreu ${ }^{8}$. Disso se é informado pela

\footnotetext{
7 Auerbach compara o estilo da escrita grega antiga com o estilo da escrita judaica do relativamente mesmo período, e conclui que, no caso da judaica, a concentração narrativa se dá apenas quanto ao essencial, impondo ao leitor/ouvinte a máxima atenção e procedimentos ativos de interpretação, no sentido de acompanhar a intenção narrativa (AUERBACH, E. A cicatriz de Ulisses, In: AUERBACH, E. Mimesis. A representação da realidade da literatura ocidental. 6 ed. São Paulo: Perspectiva, 2013, p. 9).

8 Nos termos da leitura do texto e da tentativa de compreender seu enunciado, não se precisaria realmente recorrer à observação já mencionada de Alonso-Schökel e Carniti, mas pode-se ratificar a percepção do cerco com o comentário dos autores, quanto a tratar-se, eventualmente,
} 
expressão "do que te sitiava" (חנָָּ). O tu mencionado encontrou-se - "lá" - sob cerco militar9. Logo, o "lá" se refere tanto ao lugar-evento, o cerco, quanto ao tempo, quando o cerco se deu. Lá, portanto, significa durante o cerco, de sorte que o verso poderia ter começado assim: "lá, no cerco". Mas, auerbachianamente, basta o "lá", e o leitor, se operar algebricamente, poderá lidar bem com a narrativa.

E o que houve "lá"? Eles se "aterrorizaram-se de terror"

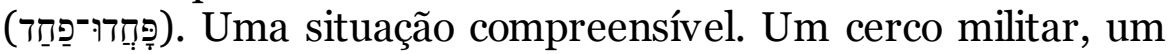
tu, um eles, e a experiência do terror. O terror deriva das circunstâncias, obviamente. Terror do cerco. Terror diante da visão terrível do exército acampado contra a cidade, contra o tu, contra o eles. Porque se encontravam sitiados, compreensivelmente, "lá, aterrorizaram-se de terror". Obviamente, esperavam pelo pior.

O texto, todavia, informa que não houve o pior, e informa-o por meio de duas notas: "sem que houvesse terror"

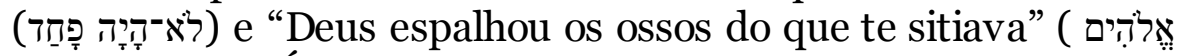

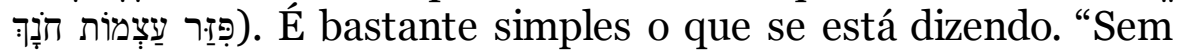
que houvesse terror" é uma forma elíptica de dizer "sem que houvesse razões para sentir terror”. O que, à primeira vista, poderia parece incompreensível, porque, se a cidade estava cercada por um exército, então havia, sim, razão para se experimentar terror. Todavia, o salmista está escrevendo não durante o cerco, ma depois dele, e, agora, quando escreve, já está informado dos acontecimentos que se deram imediatamente antes, durante e imediatamente depois do cerco, e ele sabe que o cerco foi mal sucedido, que, seja lá o que isso na prática signifique, "Deus espalhou os ossos do que te sitiava". Nesse caso, o salmista está informado de que houve o cerco, de que o tu e o eles apavoraram-se, com a iminência da morte, e, que, no entanto, o pavor que experimentaram revelou-se inapropriado, porque o cerco não logrou êxito. Nos

do sítio de Jerusalém, pelos assírios, em 701 a.C. (ALONSO-SCHÖKEL e CARNITI, 1996, p. 718). A simples leitura do texto não permite afirmar tratar-se desse cerco, mas permite considerar tratar-se de um cerco.

9 Para a ex pressão em análise, como significando "cerco militar", "sítio", cf. ALONSO-SCHÖKEL, Dicionário bíblico hebraico-português. São Paulo, Paulus, 1996, p. 233. 
seus termos, "Deus espalhou os ossos do que te sitiava", de sorte que o cerco foi encerrado, a cidade, preservada, o tu e o eles, salvos, e o terror, consequentemente, revelado infundado. Mais infundado ainda deve ser considerado tanto mais se leva em conta que o tu e o eles deveriam ter confiado na divindade. Afinal, a divindade interveio e debelou o cerco: "Deus espalhou os ossos do que te sitiava”. No final das contas, o terror que o tu e o eles experimentaram deveu-se à falta de confiança na divindade. Se, desde os primeiros movimentos do exército inimigo, tu e eles tivessem confiado em "Deus”, não teriam tido razões para experimentarem o terror que efetivamente experimentaram. Esse, pelo menos, é o raciocínio do salmista: "lá, aterrorizaram-se de terror, sem que houvesse terror, porque Deus espalhou os ossos do que te sitiava", isto é, "lá (durante o cerco, porque consideraram que seriam mortos), aterrorizaram-se (o tu e o eles) de terror, sem que houvesse terror, porque Deus espalhou os ossos do que te sitiava”.

O salmista dá a saber aos seus ouvintes que, no final das contas, a cidade estava sob a proteção do deus da cidade. Quando o exército cercou a cidade, o deus da cidade teria dito: "aqui não entrarão", e isso quer dizer que "Deus os rejeitou"

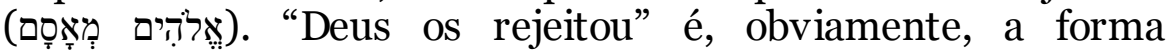
teológica de o salmista ler os acontecimentos que se traduziram no insucesso militar dos sitiadores. Após o cerco, o salmista faz a leitura teológica que, segundo ele, o tu e o eles deveriam ter feito antes e durante o cerco: “'Deus' não permitirá que a cidade seja invadida!”. Seja como for, não o fizeram, não tiveram um pingo de confiança no deus da cidade, e, por isso, experimentaram o terror que experimentaram. Não há qualquer contradição na narrativa, quando se diz que havia terror, sem que houvesse razões para haver terror. Mais uma vez, como se aprendeu de Auerbach, está-se diante do estilo narrativo próprio do escopo literário judaico do período veterotestamentário: concentração no fio narrativo, sem desviar o olhar para qualquer lado do caminho, deixando ao encargo do ouvinte/leitor o processo de concatenação 
discursiva ${ }^{10}$. Em que pese tal fato, é plenamente possível a concatenação discursiva com base no próprio texto, e isso independentemente de conhecerem-se as observações de $A$ cicatriz de Ulisses.

Finalmente, o terror que o tu e o eles experimentaram teve consequências. A primeira delas é a publicidade desse terror. O salmista sabe que o tu aterrorizou-se. E sabe, porque a informação chegou-lhe aos ouvidos, ou aos olhos, a depender de ser ele uma testemunha ocular ou apenas alguém bem informado. Seja como for, o salmista não deve ter sido a única pessoa a saber que o tu foi tomado de terror. A última seção do verso começa com uma declaração categórica: "tu te

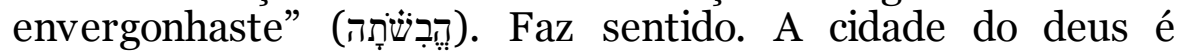
cercada. Dentro dela, sitiado, o tu deveria ter confiado no deus da cidade, mas, em lugar disso, tomado de total falta de confiança, eis que é presa total do terror, que o salmista praticamente desenha, empregando três vezes a mesma raiz: "aterrorizaram-se de terror, sem que houvesse terror". O terror do $t u$ se torna patente a todos na cidade. O tu se apavora, se amedronta, se acovarda. O cerco avança. O terror se agrava. A morte é certa. Súbito, o que o tu deveria saber desde o início, o deus da cidade intervém e salva a cidade do destino terrível. O terror se revela infundado. $O$ terror se transforma em vergonha. O tu perdeu uma excelente oportunidade de revelarse corajoso, confiante, um homem à altura dos desafios da cidade. E, todavia, ei-lo amedrontado, apavorado, aterrorizado... Vergonha!

O tu deveria saber que o deus da cidade rejeitaria os sitiadores. É essa a última declaração do salmista, no verso: "Deus os rejeitou" (אֶלֶהים מְאָסָם:). Na prática, o cerco revelou-se frustrado. Caso o cerco fosse bem sucedido, ao tu sobreviria a desgraça completa, a morte, eventualmente. Por isso, o tu aterrorizou-se. Fez as contas, vai morrer. No entanto, como o cerco foi frustrado, o tu se cobriu de vergonha. Por quê? Porque o sucesso da cidade, sua preservação, constitui vergonha para o tu que a preside? Ora, justamente porque o $t u$

\footnotetext{
10 "Os pontos culminantes e decisivos para a ação são os únicos a serem salientados; o que há entre eles é inconsistente; tempo e espaço são indefinidos e precisam de interpretação" (AUERBACH, 2013, p. 9).
} 
comportou-se de modo covarde, aterrorizado. Por isso, a acusação categórica do salmista: "tu te envergonhaste". O tu está coberto da vergonha com que ele mesmo se cobriu, quando, "lá, aterrorizaram-se de terror, sem que houvesse terror".

Um texto perfeitamente claro, lógico, muito bem concatenado. A despeito das características auerbachianas da narrativa, qualquer pessoa minimamente habilitada para a leitura vernacular poderia facilmente interpretar o texto, desde que a tradução fosse adequada. "Lá, aterrorizaram-se de terror, sem que houvesse terror, porque Deus espalhou os ossos do que te sitiava. Tu te envergonhaste, porque Deus os rejeitou" não tem qualquer indicativo objetivo de constituir uma narrativa mal preservada.

Pois bem, essa é a leitura que se pode fazer da narrativa, recorrendo-se única e exclusivamente aos termos que a compõem e à relação sintática entre eles, o que naturalmente depende de a tradução ser o mais literal e fiel possível em relação à língua em que se encontra vertido. Nesse sentido, como se comportam as versões?

2. Análise de versões brasileiras do $\mathrm{Sl}$ 53,6

Para fins de análise, serão consideradas dez seguintes versões brasileiras do Sl 53,6, aqui indicadas por suas respectivas siglas, com indicação em nota da edição correspondente: $\mathrm{AM}^{11}, \mathrm{NBP}^{12}, \mathrm{CNBB}^{13}, \mathrm{BJ}^{14}, \mathrm{BP}^{1} 5, \mathrm{MD}^{16}, \mathrm{TEB}^{1} 7$, $\mathrm{ARA}^{18}, \mathrm{ARE}^{1} 9 \mathrm{e} \mathrm{NVI}^{2} \mathrm{O}$.

${ }_{11}$ BÍBLIA SAGRADA. Tradução dos originais grego, hebraico e aramaico mediante a versão dos Monges Beneditinos de Maredsous (Bélgica). 211 ed. São Paulo: Ave Maria, 2017.

12 NOVA BÍ BLIA PASTORAL. São Paulo: Paulus, 2014.

13 BíBLIA SAGRADA. Tradução da CNBB, com introduções e notas. São Paulo: Ave Maria, Loyola, Salesiana, Paulus, Paulinas; A parecida: Santuário e Petrópolis: Vozes, 2001.

14 A BÍBLIA DE JERUSALÉM. São Paulo: Paulus, 1985.

15 BÍBLIA DO PEREGRINO. São Paulo: Paulus, 2002.

16 BÍBLIA. Mensagem de Deus. São Paulo: Loyola, 1989.

17 BÍBLIA. Tradução ecumênica. 2 ed. São Paulo: Loyola, 1995.

18 A BíBLIA SAGRADA. Traduzida em português por João Ferreira de Almeida. Revista e atualizada no Brasil. 2 ed. Barueri: SBB, 1993. 


\begin{tabular}{|l|l|}
\hline Sl 53,6 & $\begin{array}{l}\text { "Foram tomados de terror, não havendo nada para } \\
\text { temer. Porque Deus espalhou os ossos dos que te } \\
\text { assediam; foram confundidos, porque Deus os } \\
\text { rejeitou" }\end{array}$ \\
\hline NBP21 "Então eles haverão de sentir medo, mesmo sem ter \\
motivo para se apavorar. Pois Deus espalha os ossos \\
de quem sitiava você, e você os envergonha, pois é \\
Deus que os despreza".
\end{tabular}

19 A BÍBLIA SAGRADA. Versão revisada da tradução de João Ferreira de Almeida, de acordo com os melhores textos em hebraico e grego. São Paulo: Candeia; Rio de Janeiro, IBB, 2000. 20 BÍBLIA SAGRADA. Nova Versão Internacional. São Paulo: Sociedade Bíblia Internacional, 2000.

${ }^{21}$ NOVA BÍBLIA PASTORAL. São Paulo: Paulus, 2014. 


\begin{tabular}{|l|l|}
\hline $\begin{array}{l}\text { motivo algum para termer! Pois foi Deus quem } \\
\text { espalhou os ossos dos que atacaram você; você os } \\
\text { humilhou, porque Deus os rejeitou". }\end{array}$ \\
\hline
\end{tabular}

Para todos os efeitos, a BP simplesmente descartou a versão hebraica do Sl 53,6, e a substituiu, na prática, pela correspondente seção do Sl 14,5-6: "pois terão de tremer, porque Deus está com os justos; o desígnio do desvalido os confunde, porque o Senhor é o refúgio dele". Ressinto-me de condenar a prática, já que, como se viu acima, autores renomados desconsideraram sequer a necessidade de comentar em separado do Sl 53. Seja como for, considero-a inadequada. Além disso, como desconsiderou a versão hebraica do Sl 53,6 e a substitui pela versão do Sl 14,5-6, na prática a BP destrói toda e qualquer possibilidade de seu 0 leitor efetivamente entender o Sl 53, se com Sl 53 queremos nos referir ao que o texto hebraico dessa composição tem a dizer... Logo, não há o que comentar. Eventualmente, a lamentar.

Analisemos, então, as versões que ao menos tentaram efetivamente uma tradução. De início, deve-se dizer que esse não é o caso da MD: "ei-los a tremer de súbito; por que tremem sem motivo? Dispersa o Senhor seus ossos, repele e confunde os maus". O v. 6 do Sl 53, na $\mathrm{MD}$, não é uma tradução do texto hebraico do Sl 53,6. É no máximo uma paráfrase que, todavia, descaracteriza totalmente o verso. Ao leitor que tenha em mãos a $\mathrm{MD}$, e não tenha a mínima noção do texto hebraico, resulta impossível compreender seja o verso em si seja o salmo no qual ele se encontra. O cerco, simplesmente, desapareceu, e, com ele, toda e qualquer possibilidade de compreensão histórico-crítica do Sl 53,6.

Restam, assim, as demais versões. Observem-se as traduções: "você os envergonha" (NBP), "você os humilhou" (NVI), "tu os envergonhas" (BJ, ARA), "tu escarneceste deles" (TEB), "tu os confundirás" (ARE), "ficaram confusos” (CNBB) e "foram confundidos" (AM). A CNBB e a AM destoam do conjunto: respectivamente, "ficaram confusos" $\mathrm{e}$ "foram confundidos". O sujeito do verbo é dado como eles. No 
hebraico, é tu. As duas versões alteraram a pessoa que rege o verbo. Todas as demais versões pressupõem o $t u$, ainda que na sua simplificação vernacular, você. Além disso, todas essas igualmente pressupõem que o verbo exerce predicação sobre um objeto, ora constituindo esse objeto o pronome "os", ora a contração "deles". O tu ou os humilha, ou os confunde, ou os envergonha, ou, ainda, escarnece deles. Pois bem, a expressão hebraica que essas versões traduzem é הֶבְשָָׁה Trata-se da atualização Hifil, no perfeito ou completo, da segunda pessoa do singular da raiz בוש, e não há qualquer sufixo pronominal agregado ao verbo. Sem discutir se se deve traduzir בוש por "envergonhar", "confundir", "humilhar" ou "escarnecer", devese perguntar às versões de onde tiraram os pronomes sobre os quais a ação verbal se constrói nas suas respectivas traduções. Quando a mesma raiz ocorre no Sl 119,31, e se pode traduzir

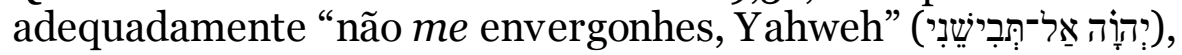
o "me" encontra-se grafado na forma de sufixo ao verbo, de sorte que a vergonha que o verbo expressa recai sobre o sufixo "me". No caso do Sl 53,6, não há sufixo pronominal. Se eventualmente se quiser argumentar que essa ausência se deveria explicar por força de economia textual ou estilo de redação, imediatamente se deve trazer à tona o fato de que, no final do mesmo verso, a expressão מุo o desmente. atualização de Qal, também no perfeito, na terceira pessoa, masculino, singular, da raiz מאס, acompanhada do sufixo de

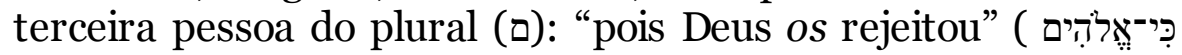
帒). Não se trata nem de economia nem de estilo. Nesse caso,

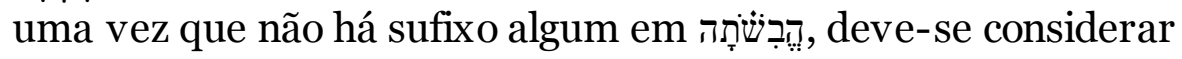
que os pronomes que as traduções inseriram nas suas respectivas versões resultam inapropriados. O verbo pode ser transitivo, como de fato é, mas não há qualquer objeto explicitado, nenhum "os", nenhum "eles", sobre os quais a transição e a predicação estejam incidindo. Nesse caso, sintaticamente falando, como o verbo é de fato transitivo, resta experimentar a transição verbal em modo reflexivo. Assim, uma vez que o sujeito do verbo é tu, salvo melhor juízo, a tradução deve ser "tu te envergonhaste".

Em termos contextuais, "tu te envergonhaste" faz sentido, especialmente se, como se viu, considerarmos a observação da 
nota h do Sl 53,6, da TEB: "diversamente do Sl 14,5-6, este v. se dirige a um representante da nação". Deve-se concordar. O $t u$ indica o representante da cidade sitiada. No v. 7, fica-se sabendo tratar-se de Sião. Ora, o representante da cidade, então, é o rei, o rei de Jerusalém, o que justifica a já mencionada hipótese que Alonso-Schökel e Carniti lançam sobre tratar-se do cerco de Senaqueribe, situação em que o tu do Sl 53,6 seria ninguém menos do que Ezequias. Sendo ou não o caso, durante o cerco, o tu, isto é, o rei deveria ter-se dirigido ao muro da cidade, deveria ter demonstrado coragem, confiança, destemor, e, todavia, revelou-se, como se viu, medroso, apavorado, covarde. Noutras palavras, ou, nas palavras do salmista: passou vergonha. Que oportunidade de ouro perdida! Era para o rei sair carregado nos braços do povo, e, todavia, sai, por sua própria culpa e covardia, envergonhado: "tu te envergonhaste".

O raciocínio é simples, e já foi antecipado acima. "Tu te envergonhas" se dirige ao tu da cidade, ao rei. Ele se envergonhou, porque se apavorou durante o cerco. Apavorouse, porque se acovardou. Mas, sempre nos termos do raciocínio do salmo, se houvesse confiado no deus de Sião, então teria experimentado não terror, mas coragem, e estaria, agora, glorificado. Como não, sai envergonhado. "Tu te envergonhaste", justamente "porque Deus os rejeitou”. Não houvera o deus da cidade rejeitado os sitiadores, o terror do rei não teria sido debalde, estaria ele agora morto, fim da história. Mas a cidade foi poupada. Sua covardia, revelada. Sua vergonha, notória. As versões não entenderam assim. Não entendendo assim, operaram o verbo הִּבְשָתָה como transitando para o objeto "eles". Por exemplo: "tu os envergonhas". Assim, aquele que é um "tu" achacado de vergonha, nas versões se transforma em um sujeito que faz com que outros passem vergonha, não ele. Na prática, as versões alteraram a história. Deve-se considerar se não foi o caso de as lacunas auerbachianas do Sl 53,6 terem constituíram desafio mais difícil do que o compositor poderia ter desejado. É até compreensível, já que falta ao tradutor o contexto prosódico da leitura pública, e o contexto prosódico carrega significativa carga semântica performática. Diante do tumular silêncio do 
texto, porque, nesse sentido, sim, está morto o autor, literalmente, deve o tradutor emular sentidos históricos, enunciações datadas, e, indiciariamente, tentar recuperar o sentido "arqueológico" do discurso. O que nem sempre é fácil, e, de qualquer forma, verificável apenas em termos retóricos.

A avaliação do conjunto das versões não é boa. Apenas a CNBB e a BJ levaram mais ou menos a sério o fato de que o verso hebraico começa com uma cláusula adverbial, e incluíram a palavra "lá" em suas traduções. Talvez a NVI tenha tentado um efeito semelhante, quando incluiu uma interjeição imperativa: "olhem!", na abertura do verso. Mas comete uma impropriedade, porque, ao incluir o imperativo, presentifica o terror mencionado, quando, a rigor, ele já passou, sabe o salmista disso, e sabem-no os leitores. E, de qualquer forma, ainda que a NVI queira que o leitor "olhe", deveria, nesse caso, apontar para onde. E esse onde seria justamente o "lá" que abre o verso. As gramáticas de hebraico ensinam que, no contexto da Bíblia Hebraica, a alteração dos termos da oração implica em ênfase. Ora, a ordem sujeito, verbo e predicado foi alterada, e um dos elementos do predicado, uma cláusula circunstancial de tempo e lugar, foi antecipada a todos os demais elementos da oração. Isso quer dizer que a palavra mais importante da oração é essa - שָׁם ("lá”). E, no entanto, com exceção da CBNN e da BJ, e a despeito de eventual esforço da NVI, tanto esta quanto todas as demais simplesmente desconsideraram a cláusula adverbial que abre o verso. O cerco tornou-se insignificante. $\mathrm{O}$ evento que é a causa e a chave do $\mathrm{Sl}$ 53,6 , simplesmente dissolve-se em uma inadequada conversão do código retórico da língua traduzida para o código retórico da língua para a qual se traduz. Em termos figurativos, não deixa de ser uma violência.

Disse-se que o cerco foi diminuído em seu significado retórico no verso. Isso pode ser evidenciado inclusive plasticamente. A imagem de um cerco militar a uma cidade inexiste na tradução da $\mathrm{BP}$ e na da $\mathrm{MD}$, e dissolve-se na tradução da AM ("te assediam") e da NVI (")dos que atacaram você). "Assediar" e "atacar" não levarão jamais o leitor a imaginar tratar-se, no nível do hebraico, de um cerco militar. Mais uma vez, a possibilidade de compreensão da passagem 
diminui. É de registrar, todavia, que as demais versões mantiveram a ideia de cerco militar, traduzindo a expressão hebraica como "sitiar".

No conjunto, parece adequado concluir que tanto o recorte da pesquisa de Salmos analisado (Kraus, Weiser, Alonso-Schökel e Carniti), quanto as versões brasileiras, lidaram inadequadamente com Sl 53,6. Os comentaristas, porque, considerando tratar-se a passagem de um texto mal preservado, abandonaram-no, concentrando-se apenas no Sl 14. As versões, como se viu, quando não porque, da mesma forma como os comentaristas mencionados, desprezam a versão do Sl 53,6, substituindo-a pela do Sl 14,5-6, então porque desconsideram os códigos retóricos do texto hebraico e porque acrescentam pronomes-objetos que não existem no texto.

Não é tarefa difícil indicar nos demais versos do $\mathrm{Sl} 53$ das versões analisadas, os indícios da violência no processo de tradução. Não há espaço aqui para isso. Mas é preciso mencionar que o Sl 53,6 não se encontra sozinho: as mesmas citadas versões comportam-se de modo igualmente inadequado, quando lidam com o v. 3 e entreveem ali a "humanidade", o v. 5, e enxergam ali uma cláusula de comparação, e o v. 7, quando transformam um plural hebraico em um singular vernacular - "salvação", "livramento" ou "vitória". A violência que o Sl 53,6 sofre é apenas um momento de um processo violento maior, que enclausura o salmo em uma cápsula teológica e, distanciando-se dos sinais marcados na página, pedindo decodificação histórico-crítica, operam interpretações mais próprias dos contextos de recepção da leitura do texto do que se seu mundo de produção.

\section{Conclusão}

Ambos constituindo duas versões diferentes da mesma composição, o Sl 53 tem sido considerado como secundário em relação ao $\mathrm{Sl}$ 14, bem como um texto mal preservado (Kraus, Weiser, Alonso-Schökel e Carniti). Analisadas dez versões brasileiras do $\mathrm{Sl} 53,6$, conclui-se que as traduções oferecidas deixam a desejar em dois aspectos fundamentais: a) ou, na 
prática, substituem mais ou menos explicitamente o $\mathrm{Sl}$ 53,6 pelo Sl 14,5-6, ou b) afastam-se da literalidade do texto, sob pretexto de que se encontra mal preservado, incluindo elementos que não o constituem materialmente, alterando sujeitos verbais, negligenciando códigos sintático-retóricos e dissolvendo o contexto narrativo de modo mais ou menos irrecuperável. Em alguns casos, não se pode sequer mais dizer tratar-se mesmo do Sl 53,6. Noutros, ainda se pode empreender algum esforço de compreensão, conquanto, dado o afastamento mencionado em relação ao texto hebraico, a possibilidade de entendimento do que a narrativa hebraica do Sl 53,6 diz seja bastante remota. Mesmo as versões mais literais, pelo fato de, todas, terem transformado o $t u$ que se envergonha em um tu que faz terceiros se envergonharem, produziram um resultado que dificilmente ajudará o leitor a compreender o que o salmista efetivamente quis dizer. Quer dizer, se é disso que se trata, quando se vão ler os textos da Bíblia Hebraica...

\section{Referências}

Bíblias

A BÍBLIA DE JERUSALÉM. São Paulo: Paulus, 1985.

A BÍBLIA SAGRADA. Traduzida em português por João Ferreira de Almeida. Revista e atualizada no Brasil. 2 ed. Barueri: SBB, 1993.

A BÍ BLIA SAGRADA. Versão revisada da tradução de João Ferreira de Almeida, de acordo com os melhores textos em hebraico e grego. São Paulo: Candeia; Rio de Janeiro, IBB, 2000.

BÍBLIA DO PEREGRINO. São Paulo: Paulus, 2002.

BÍBLIA SAGRADA. Nova Versão Internacional. São Paulo: Sociedade Bíblia Internacional, 2000.

BÍBLIA SAGRADA. Tradução da CNBB, com introduções e notas. São Paulo: Ave Maria, Loyola, Salesiana, Paulus, Paulinas; Aparecida: Santuário e Petrópolis: Vozes, 2001. 
BÍBLIA. Mensagem de Deus. São Paulo: Loyola, 1989.

BÍBLIA. Tradução ecumênica. 2 ed. São Paulo: Loyola, 1995.

NOVA BÍBLIA PASTORAL. São Paulo: Paulus, 2014.

\section{Bibliografia}

ALONSO-SCHÖKEL, L. e CARNITI, C. Salmos I. Salmos 1-72. São Paulo: Paulus, 1996.

AUERBACH, E. A cicatriz de Ulisses, In: AUERBACH, E. Mimesis. A representação da realidade da literatura ocidental. 6 ed. São Paulo: Perspectiva, 2013.

KRAUS, H. Los Salmos. Volumen I. Salmos 1-59. Salamanca: Sígueme, 2009

TREBOLLE BARRERA, J. A Bíblia judaica e a Bíblia cristã. 2 ed. Petrópolis: Vozes, 1999.

WEISER, A. Os Salmos. São Paulo: Paulus, 1994. 